\title{
Enhancement of Radiation Safety in Industrial Cobalt -60 Irradiator During Abnormal Conditions
}

\author{
A. Hamza Khalifa ${ }^{1}$, Keshek A. $B^{2}$ and Bassam W. Abou-Shousha ${ }^{3}$ \\ ${ }^{1}$ Safety of Fuel Cycle Department, Nuclear and Radiological Regulatory Authority. Egypt. \\ ${ }^{2}$ Radiation Engineering Department, N C R RT. Atomic Energy Authority - Cairo. Egypt \\ ${ }^{3}$ Engineering High Institute - El-Shrouk. - Cairo. Egypt
}

\begin{abstract}
Enhancement of radiation safety in industrial cobalt -60 irradiator unit is a necessity need to protect working staff and the environment against radiation release by applying radiation safety standards inside and outside industrial during normal and abnormal operating conditions. This could be fulfilled by preventing stacking, falling, and probability broken cobalt-60 radiation capsules which could lead to water contamination inside the storage pool. The water of storage pool is contaminated by broken hot capsule where the radiation source is changed from close radiation source to very dangerous open radiation source. This paper presents a proposed modified design with concrete shielding maze having more than one right - angle bend to maintain radiation prohibitive and to determine the smallest radiation exposure rates at the entrance of maze design with several legs.
\end{abstract}

High standards of radiation safety are maintained by the proposed design through safe containing water treatment plant (deionizer plant) which is located safely inside the proposed design. Safe steel shielding sliding door is attached with the proposed design and depending on maze idea. Electrical control system (programmable logic safety controller P.L.C) is incorporated with the steel door design; the recirculation pump is located near control panel to maintain radiation safety for operation and control during the probability of radiation contamination for water storage pool by broken hot cobalt -60 capsules. The deionizer system was equipped by an electronic sensor to automatically close or lock the door of the deionizer room and switch off the pump to prevent the discharge of deionizer wastewater to the normal sewage to prevent the public and environment pollution. Monte Carlo calculations have been carried out for the new proposed design that is attached by cobalt-60 industrial irradiator using complex geometry. The threedimensional flux is calculated at different positions from which the gamma volume is monitored for these positions. All radiological measurements in case of normal operation and abnormal operation after the proposed design are safe.

Key words: Gamma Irradiator Facility, Nuclear Safety, Wet Storage Irradiator, Cobalt-60, Security Systems.

\section{INTRODUCTION.}

Success of industrial irradiation processing is maintained globally throughout good design [1], development and attachment of radioactive source, the source hoist mechanism, the product transport mechanism and specialists to keep and increase radiation safety standards. However, some major problems are recorded in some irradiators in different countries around the world $[2,3]$. One of these problems is source stuck between source rack and horizontal product conveyors and probability broken cobalt-60 radiation capsules [4] which could lead water contamination inside storage pool. 
Figure1.shows a schematic diagram of wet storage irradiators [5] where the products can be loaded into large product boxes (carton, fibber or tote). The products boxes are trances by pneumatic cylinders (pushers) around vertical radiation cobalt-60 which are located on a vertical source rack [6]. The source rack holds cobalt-60 in the form of source pencils.

In wet storage irradiators, water is used as a radiation shielding medium. The water column has three functions: the first and most important is as radiation shielding; the second is to restrict human access to the source and to the volume under irradiation; the third is dissipating the heat generated by the source (via naturally-formed convection currents), [7].
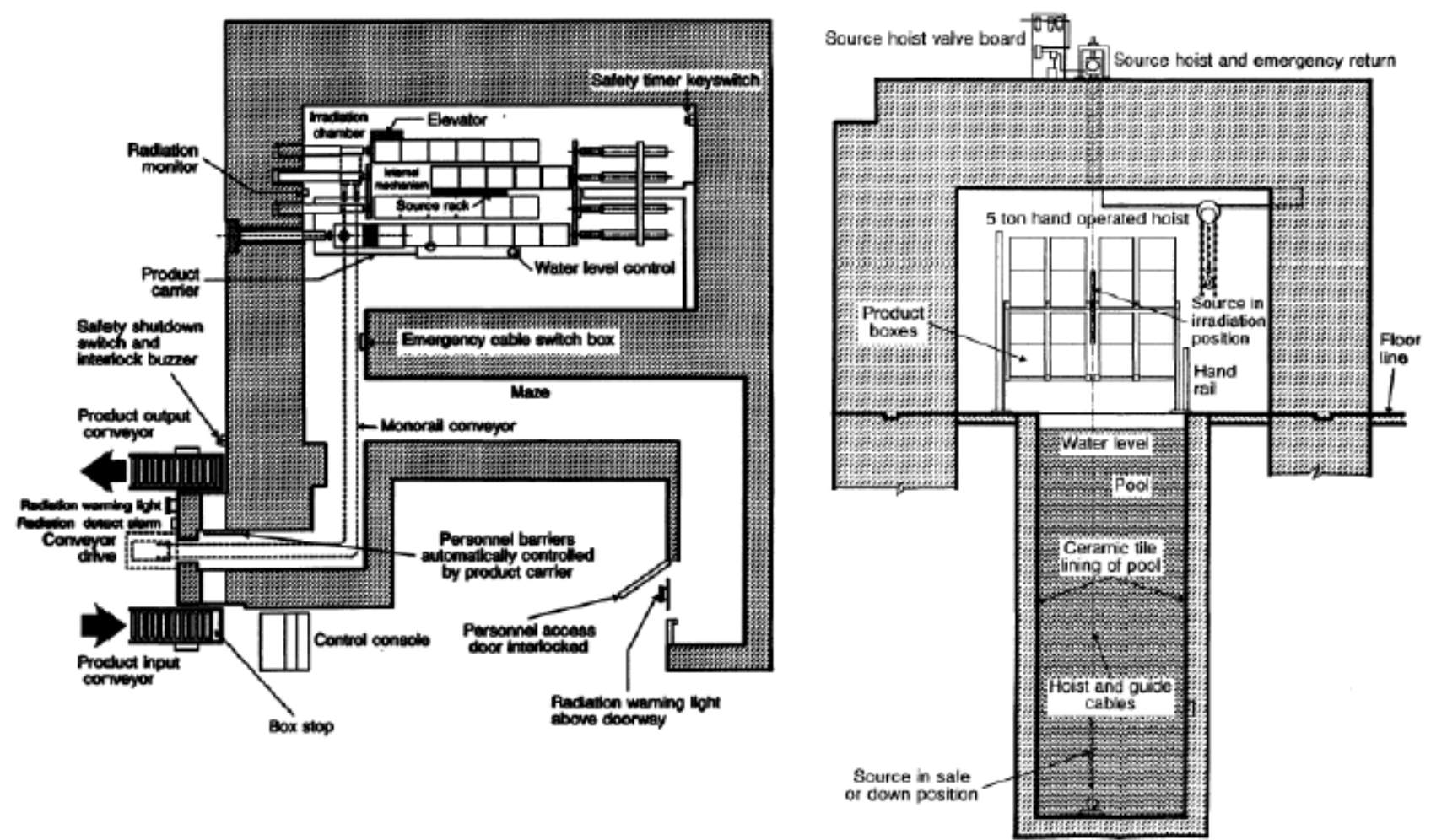

Figure 1: Schematic diagram for Plan and Side view of J.S 9500 Wet storage Canadian irradiator.

In wet-storage pool of this irradiation facility, the integrity of the pool and the use of corrosion resistant pool components have to be ensured. Water level control with visible and audible signals has to be provided for such cases when the water level falls to more than $30 \mathrm{~cm}$ below the normal level. Furthermore, automatic water replenishment, water cooling, water conditioning system with conductivity control, external high flow rate water supply has to be provided. To protect personnel a physical barrier has to be built along the pool $[8,9]$.

\section{COBALT-60 IRRADIATOR, MAIN COMPONENT REVIEW.}

\subsection{Radiation Source.}

The radioactive cobalt- 60 source irradiator is the main radiation source which activity one mega curie and its elements are contained by doubly encapsulated stainless source pencils. The unit source rack arrangement with six source modules, each containing up to 42 source pencils with two standard source elements in each pencil. The target capsules are Cobalt-60 or dummy which are arranged in their modules in the source rack. One pencil (capsule) is about 400 gram weight; $45.2 \mathrm{~cm}$ length and $11.1 \mathrm{~mm}$ diameter.

The Cobalt-60 capsules have intense blue light due to Cerenkov radiation that is visible in the storage pool when the source rack is submerged [2,3,4]. This arrangement is depicted in Figure 2. The source rack should be designed so that there are no crevices in the source holder, or between the radioactive source and the source holder, that would promote corrosion. [8, 9]. 


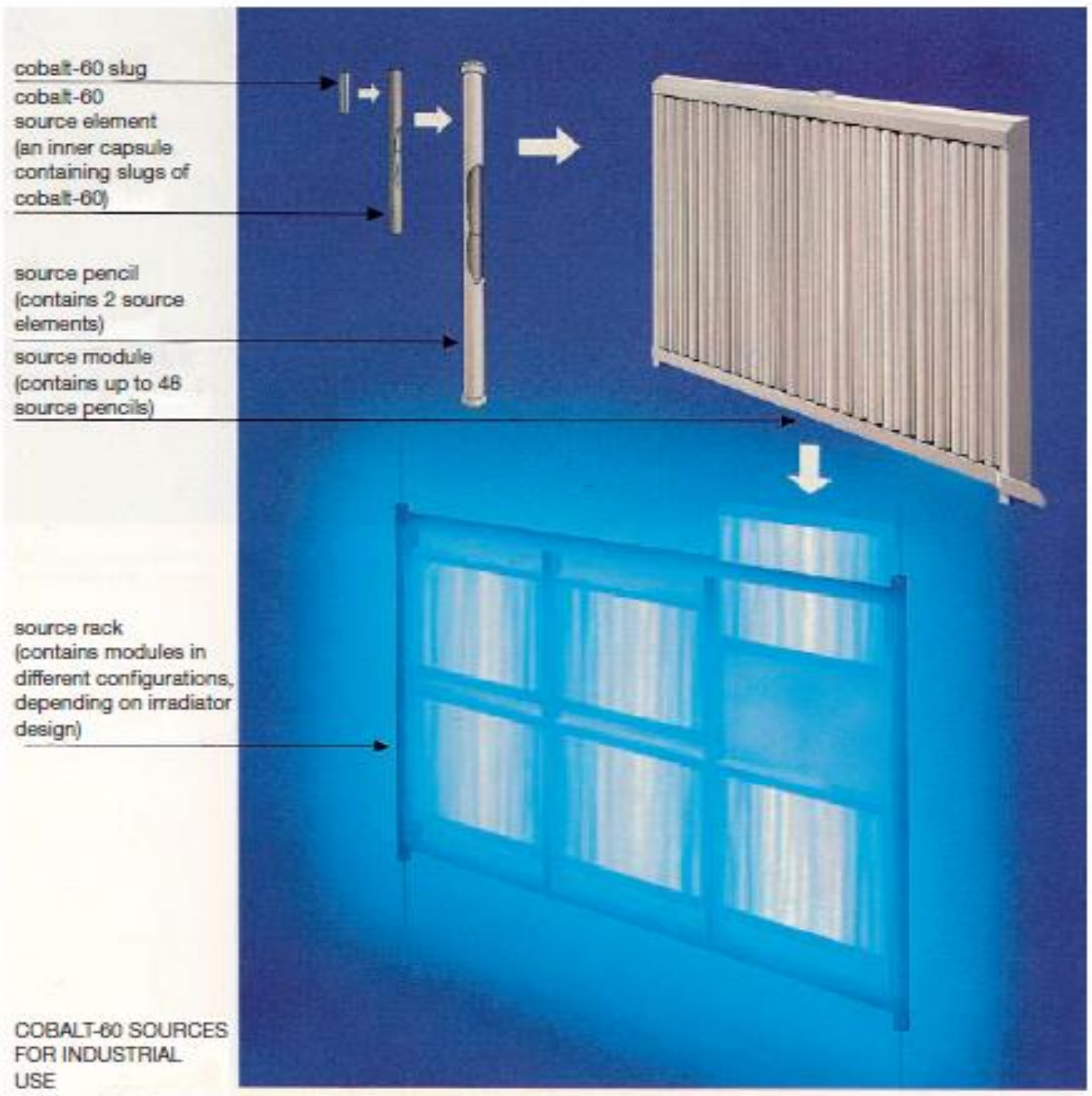

Figure2: Schematic showing the build-up of a typical cobalt source rack from slugs, pencils and modules (courtesy of MDS Nordion, Canada).

\subsection{Radiation concrete shielding and the storage pool.}

The concrete radiation shielding is designed to reduce the radiation leakage level from inside to outside industrial irradiator according to international standards of radiation protection for personals. The calculated thickness of concert shielding depends on the activity of radiation source and distance between radiation source rack and irradiator concrete shielding so as to maintain the radiation level at the location of the control console close to natural background. Also, it must include multiple safeguards to protect operator health and the community should a natural disaster like an earthquake, fire, or tornado occur $[5,10]$. The radiation shield is designed, to an average exposure rate of less than $2.5 \mu \mathrm{Sv} / \mathrm{h}(0.25 \mathrm{mrem} / \mathrm{h})$. This allows a person to work near the shield 40 hours per week and limit their exposure to a maximum dose of $5.0 \mathrm{mSv}$ (500.0 mrem) per year [11, 12 and13].

Maximum exposure rates up to $20 \mu \mathrm{Sv} / \mathrm{h}(2.0 \mathrm{mrem} / \mathrm{h})$ are allowed in small areas adjacent to the shield, provided these contributions do not raise the average exposure rate above $2.5 \mu \mathrm{Sv} / \mathrm{h}(0.25 \mathrm{mrem} / \mathrm{h})$ over any surface of concrete shielding [5, 14]. Stepped concrete plugs located in the roof are removable to allow lowering of the cobalt 60 shipping container into the source storage pool [9]. Personnel and product enter the radiation room through a maze design that loss of shield integrity or an access door $[14,15]$. Personal enter through an access door. The product is transported, by the conveyor system, through separate entry (maze) and discharge ports [15]. These ports are blocked personnel entry (maze) by metal barriers when no product is present [14, 15, 16, and 17]. 
Figures 1 and 3 show the geometry designs of industrial irradiator with all dimensions (in millimeters). The irradiator's height is three meters. All shielding walls, ceiling and canyon ground are of concrete with high density $2.3 \mathrm{gm} / \mathrm{cm}^{3}$. The ceiling thickness is 1.8 meter, while the depth of the concrete ground is one meter.

The storage pool is constructed from calculated concrete shielding and it is sited inside the floor of irradiation room. The cobalt-60 radiation source rack is stored or shielded after irradiation processing by lowering it into a safe position inside a pool of water at $5.5 \mathrm{~m}$ depth $[3,15]$ that is constructed by calculated high density concrete shielding making it a category IV irradiation under the international classification $[18,19]$. A water proof membrane is used on the exterior pool concrete walls to prevent seepage of pool water into surrounded soil and interior concrete walls of the pool are coated by stainless steel [9].

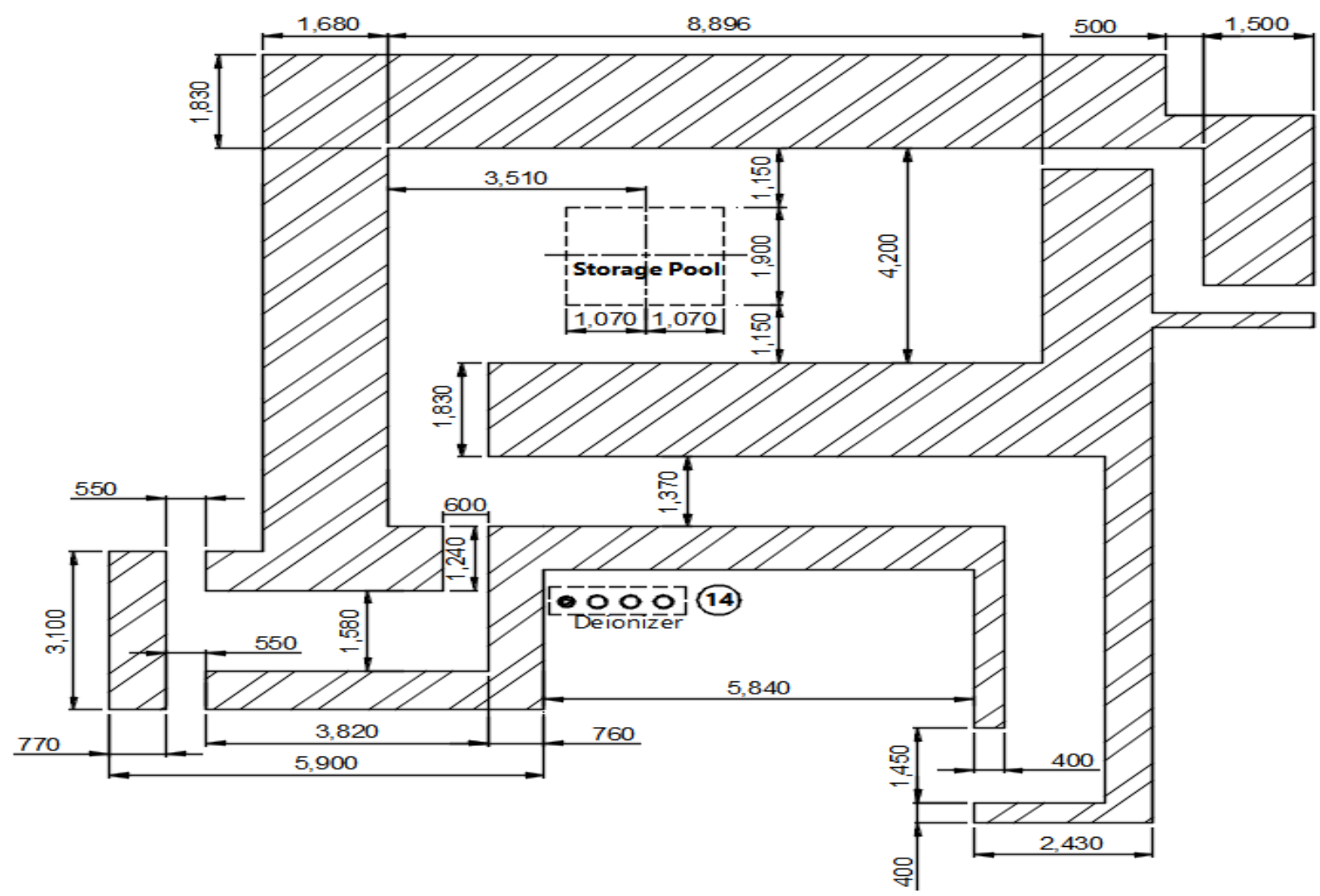

Figure 3: Plane of cobalt-60 measurement before modification.

\subsection{Source Shroud.}

A stainless steel Source Shroud completely surrounds the source when it is in the irradiate position. The shroud prevents product boxes from interfering with the source, and ensures that displaced sealed sources fall into the pool $[20,21]$.

\subsection{Radiation source mechanism.}

The radiation source is stored near the bottom of the storage pool when the unit is out of operation, and it is raised to irradiation position. The lower edge of the source rack is 0.3 meter above the ground as shown in figure 1. By a pneumatic hoist mounted on the roof of radiation shielding of the irradiator. A stainless steel hoist cable attached to source rack passes through roof concrete shield to two sets of sheaves in the hoist cylinder. When air pressure is pushed to the hoist, the sheaves separate and the source rack is lifted. The source rack movement is guided by two taut guide cables, on each end of the rack. In the raised position, radiation source rack actuates a micro switch to indicate the radiation source is up. When air is exhausted from the source hoist, the source rack is returned under gravity to the safe storage position inside storage pool. The weight of source rack pulls the sheaves in the hoist cylinder back together, detecting a micro switch mounted on hoist cylinder to indicate that radiation source rack is down $[3,20]$. 


\subsection{Recirculation pump.}

The water in the storage pool is continuously circulated through a mixed resin bed deionizer and activated carbon purifier pool to maintain the conductivity accordance between 1.0 and 10.0 micro Siemens per centimeter to reduce the possibility of corrosion of sealed source accordance with International recommendation, also the source storage pool should be cleaned as necessary to remove foreign matter that has accumulated at the bottom.

The pump is connected to an electronic buoy to monitor the water level in the source well and allows self-compensation if the water level in the well is low. Exhaust water discharge in case of exceeding it, as well as used in the discharge of water resulting from the activation and washing of the water treatment unit to public drainage [9].

\subsection{The water treatment system.}

It is designed to maintain continual neutralization and purification for water in wet storage pool inside industrial irradiator. Figure 4 shows the treatment and desalting the dissolved salts from the incoming water. The treated water contains less than $10 \mathrm{ppm}$ salts. After filling the reservoir which shut- off automatically using mechanical safety locker, water flows to feeding pump to increase water pressure before reaching the treatment unit. Carbon filter absorbs chlorine, unusual odor, impurities, and precipitants. Water passes to the cation exchange which a Calcium and Magnesium ions then the water passes to anion exchange which the dissolved conceder about $98 \%$ of the total dissolved ions. Final water contains less than 10 ppm dissolved ions. It goes to storage well of the irradiation element. The stored water rotates between the storage well, deionizer and Carbon filter using recirculation pump to maintain the level of dissolved ions. It's normally sited outside concrete shielding. These low conductivity ranges assure minimum corrosion of expensive and critical pool equipment and improve water clarity. All filters and resin beds in water treatment systems should be tested for contamination before the removal, backwashing or regeneration of the system. Fluids resulting from backwashing or regeneration should only be released if the level of contamination is below authorized limits established by the regulatory body [23].

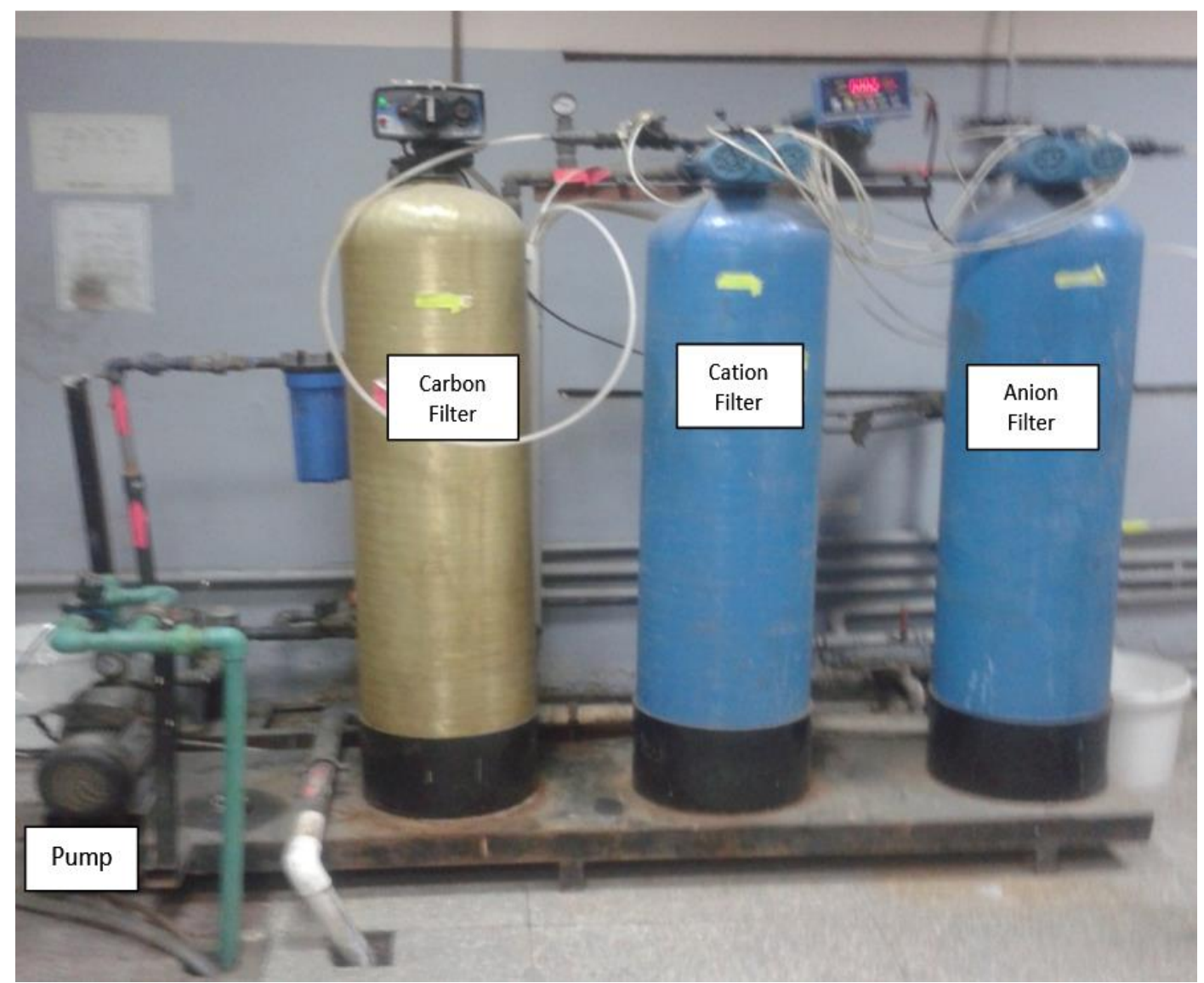

Figure 4: Photograph water treatment unit. 


\section{SCOPE OF THE RESEARCH WORK.}

\section{System problem and idea for solution.}

Probability of bending and break in any cobalt-60 capsule that falls inside storage wet irradiator maintains bad results inside storage pool wet and very dinger results are recorded in wet-storage IV-category irradiator. Water treatment plant (deionizer) is sited inside environment and outside calculated concrete shielding and it became very contaminated by gamma radiation and cobalt-60open source which passes to outside irradiator through water pipes between water storage pool inside irradiation room and water treatment plant outside irradiator. Emergency bell is ringing continuously. Environment outside irradiator becomes very danger. There is a necessity need to design and construct a proposed design that is attached with new separate maze of concrete shielding and sliding steel shielded doors which are attached to main concrete shielding of the proposed design. The proposed design will contain safely water treatment plant and will prevent high radiation exposure. Environment around proposed design is become very safe and radiation safety is maintained. The proposed design depends on radiation physics science, irradiator design engineering and environmental impact assessment, table 1 and Figure 5.

\section{SOLUTION TECHNIQUE}

\section{Primary radiation shielding elements are applied where:}

1- The exposure rate depends on the activity of radiation source and it is inversely proportional to the square of the distance.

2- Maze design, where accurate calculation of exposure rate and energy spectrum at point to long a concrete maze has been achieved as well as calculation of the attenuation rate to reduce the radiation leakage level from inside to outside industrial irradiator concrete maze has been confined for two legged concrete ducts with more than one right-angle bend.

3- Steel shielded (sliding) door systems are constructed with steel section (U), Electrical safety automatic opening / closing (P.L.C) for shielding steel door (sliding) is the most reliable well-built [24]. Electric operators (P.L.C) are specifically designed to eliminate the problems that were recorded on other design. The proposed steel door is built with the very best industrial electrical components and door inertia control (laser) are diminished or eliminated by design.

4- The Deionizer sensor will detect the presence of cobalt 60 in the unlikely event of contamination from the storage pool. Deionizer sensor fault will light up on the PLC control panel. The safety interlocks will stop the deionizer circulation pump. The unit of P.L.C. was supplied by sensors when the radiation senses [25], the door closes automatically and immediately on the contaminated water treatment system. As well as stopping the pump to prevent automatically water discharge to civil sewage.

\section{CALCULATIONS AND MEASURES DURING NORMAL, ABNORMAL OPERATIONS AND AFTER THE PROPOSED DESIGN.}

Maximum exposure rates of up to $20 \mu \mathrm{Sv} / \mathrm{h}(2 \mathrm{~m} . \mathrm{rem} / \mathrm{h})$ are allowed in small areas adjacent to the shield, provided these contributions do not raise the average exposure rate above to $2.5 \mu \mathrm{Sv} / \mathrm{h}(0.25 \mathrm{~m} . \mathrm{rem} / \mathrm{h})$ over any shielding surface $[5,14]$. Operators and products enter irradiation room through mazes design which prevents loss of shielding. Personal enter through an access door of main maze. Monte Carlo calculations are carried out for the MULTIKENO-NEW code for the gamma industrial irradiators [26]. The calculations are performed for 150 generations each with 127000 particle history. The three dimensional flux are calculated at position (1) to position (41) different positions from while the gamma volume dose was obtained for these position during normal operation, probability broken hot capsule and after proposed design is applied. The irradiator has three mazes but the proposed design has four mazes, at position 14 as indicated in the Figure 5. 


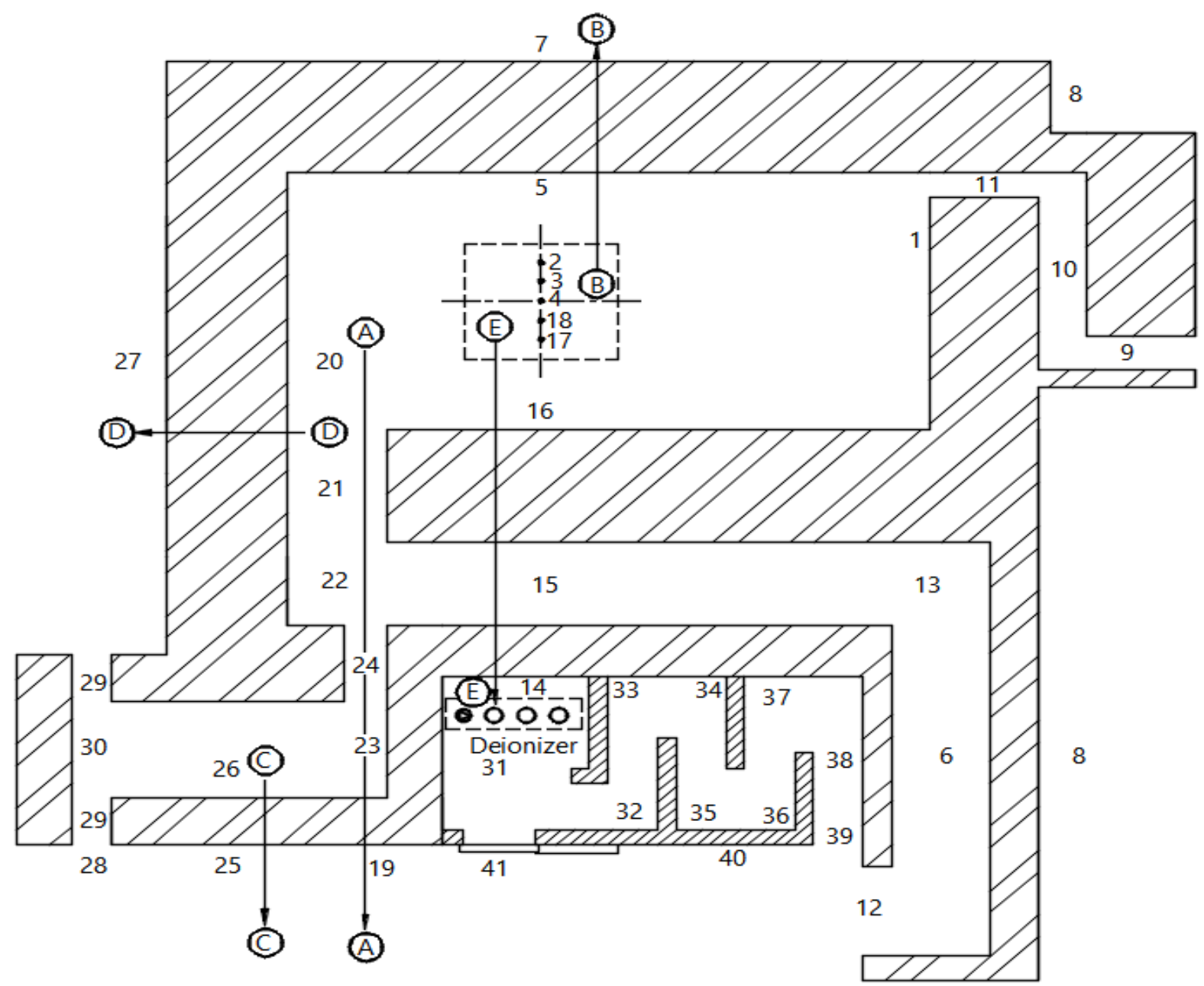

Figure 5: Volume dose on various positions inside irradiator and development.

- All positions represent volume regions. Position 4 in the source regions.

- Positions 3 and 18 are at $30 \mathrm{~cm}$ away from the source.

- Positions 2 and 17 are at $80 \mathrm{~cm}$ away from the source.

- The other positions are at $30 \mathrm{~cm}$ away from the concrete wall.

In the following are the gamma dose values as obtained by the Monte Carlo calculations arranged according to their importance from the point of view of shielding considerations:

Note: any dose value less than $0.1 \mu \mathrm{Sv} / \mathrm{h}(0.01 \mathrm{mrem} / \mathrm{h})$ could be considerate as back-ground value [26].

The first maze: is as indicated by the positions 4, 18, 17, 20, 21, 22, 24, 23, 26, 30and 29.

This maze is used for product irradiation.

$>$ The second maze: is indicated by the positions 4, 18, 17, 20, 21, 22, 15, 13, 6 and 12 .

This maze is used for facility workers.

$>$ The third maze: is indicated by the positions $4,3,2,1,11,10$ and 9 .

This maze is used for research samples irradiation.

$>$ The fourth maze: is indicated by the positions $14,31,32,33,34,35,36,37,38$, and 39.

The proposed design and its maze are used to contain water treatment plant inside them.

In the following are the results of this calculation at position 1 to position 41 , positions inside and outside the irradiators (indicated in the Figures 5 and the proposed design). 
International Journal of Engineering Research And Advanced Technology, Vol.5, Issue 4, April-2019

6. Volume dose of gamma at different position during different cases.

Table 1: Volume dose of gamma at different positions during different cases.

\begin{tabular}{|c|c|c|c|}
\hline \multirow{3}{*}{$\begin{array}{l}\text { Positions } \\
\text { Number }\end{array}$} & \multicolumn{3}{|c|}{ Volume dose (rem/h) } \\
\hline & \multirow{2}{*}{ At normal operation } & \multicolumn{2}{|c|}{ Falling broken hot capsule inside water pool } \\
\hline & & Before Modification & After modification \\
\hline 1 & 0.316 & 0.207 & 0.207 \\
\hline 2 & 10.15 & 9.25 & 9.2 \\
\hline 3 & 31.84 & 30.68 & 30.84 \\
\hline 4 & 60.10 & 59.8 & 59.8 \\
\hline 5 & 3.98 & 3.73 & 3.73 \\
\hline 6 & $\mathbf{0 . 0}$ & $\mathbf{0 . 0}$ & $\mathbf{0 . 0}$ \\
\hline 7 & $\mathbf{0 . 0}$ & $\mathbf{0 . 0}$ & $\mathbf{0 . 0}$ \\
\hline 8 & $\mathbf{0 . 0}$ & $\mathbf{0 . 0}$ & $\mathbf{0 . 0}$ \\
\hline 9 & $\mathbf{0 . 0}$ & $\mathbf{0 . 0}$ & $\mathbf{0 . 0}$ \\
\hline 10 & 0.001 & 0.0 & 0.0 \\
\hline 11 & 0.20 & 0.18 & 0.18 \\
\hline 12 & 0.0 & 0.0 & 0.0 \\
\hline 13 & 0.0 & 0.0 & 0.0 \\
\hline 14 & $\mathbf{0 . 0}$ & 0.12 & $\mathbf{0 . 0}$ \\
\hline 15 & 0.00028 & 0.00009 & 0.0009 \\
\hline 16 & 3.12 & 2.08 & 2.8 \\
\hline 17 & 10.13 & 9.02 & 9.02 \\
\hline 18 & 31.84 & 30.43 & 30.41 \\
\hline 19 & 0.0 & 0.0 & 0.0 \\
\hline 20 & 0.316 & 0.207 & 0.207 \\
\hline 21 & 0.121 & 0.019 & 0.02 \\
\hline 22 & 0.014 & 0.002 & 0.004 \\
\hline 23 & 0.00068 & 0.00049 & 0.0005 \\
\hline 24 & 0.00368 & 0.00259 & 0.0026 \\
\hline 25 & 0.0 & 0.0 & 0.0 \\
\hline 26 & $1.0 \times 10^{-6}$ & 0.0 & 0.0 \\
\hline 27 & 0.0 & 0.0 & 0.0 \\
\hline 28 & 0.0 & 0.0 & 0.0 \\
\hline 29 & 0.0 & 0.0 & 0.0 \\
\hline 30 & 0.0 & $\overline{0.0}$ & 0.0 \\
\hline 31 & \multirow{11}{*}{$\begin{array}{l}\text { Background outside } \\
\text { concrete shielding of } \\
\text { industrial irradiator } \\
\text { during normal } \\
\text { operation. }\end{array}$} & $0.12 *$ & 0.1 \\
\hline 32 & & \multirow{10}{*}{$\begin{array}{l}\text { High radiation exposure } \\
\text { as a result of falling } \\
\text { broken hot capsule where } \\
\text { water treatment plant } \\
\text { recorded high radiation } \\
\text { around it. }\end{array}$} & 0.0037 \\
\hline 33 & & & 0.0007 \\
\hline 34 & & & 0.0002 \\
\hline 35 & & & $\begin{array}{l}0.0001 \\
\end{array}$ \\
\hline 36 & & & 0.0 \\
\hline 37 & & & 0.0 \\
\hline 38 & & & 0.0 \\
\hline 39 & & & 0.0 \\
\hline 40 & & & 0.0 \\
\hline 41 & & & $\overline{0.0}$ \\
\hline
\end{tabular}


International Journal of Engineering Research And Advanced Technology, Vol.5, Issue 4, April-2019

6.1 Volume dose at various positions in the product maze.

Table: 2

\begin{tabular}{|c|c|c|c|c|c|c|c|c|c|c|c|}
\hline Position & 4 & 18 & 17 & 20 & 21 & 22 & 24 & 23 & 26 & 30 & 29 \\
\hline Dose (rem/h) & $\mathbf{6 0 . 1}$ & $\mathbf{3 1 . 8 4}$ & $\mathbf{1 0 . 1 3}$ & $\mathbf{0 . 3 1 6}$ & $\mathbf{0 . 1 2 1}$ & $\mathbf{0 . 0 1 4}$ & $\mathbf{0 . 0 0 3 6 8}$ & $\mathbf{0 . 0 0 0 6 8}$ & $\mathbf{1 0}^{-6}$ & $\mathbf{0}$ & $\mathbf{0}$ \\
\hline
\end{tabular}

6.2 Volume dose at various positions in the worker maze.

Table: 3

\begin{tabular}{|c|c|c|c|c|c|c|c|c|c|c|}
\hline Position & 4 & 18 & 17 & 20 & 21 & 22 & 15 & 13 & 6 & 12 \\
\hline Dose (rem/h) & $\mathbf{6 0 . 1}$ & $\mathbf{3 1 . 8 4}$ & $\mathbf{1 0 . 1 3}$ & $\mathbf{0 . 3 1 6}$ & $\mathbf{0 . 1 2 1}$ & $\mathbf{0 . 0 1 4}$ & $\mathbf{0 . 0 0 0 0 2 8}$ & $\mathbf{0 . 0}$ & $\mathbf{0 . 0}$ & $\mathbf{0 . 0}$ \\
\hline
\end{tabular}

6.3 Volume dose at various positions in the research maze.

Table: 4

\begin{tabular}{|c|c|c|c|c|c|c|c|}
\hline Position & 4 & 3 & 2 & 1 & 11 & 10 & 9 \\
\hline Dose (rem/h) & 60.1 & 31.84 & 10.15 & 0.316 & $\mathbf{0 . 2}$ & $\mathbf{0 . 0 0 1}$ & $\mathbf{0 . 0}$ \\
\hline
\end{tabular}

6.4 Volume does in direction across shielding.

Table 5: Volume does in direction (A) across shielding.

\begin{tabular}{|c|c|c|c|c|c|c|}
\hline Position & 20 & 21 & 22 & 24 & 23 & 19 \\
\hline Dose (rem/h) & $\mathbf{0 . 3 1 6}$ & $\mathbf{1 . 1 2 1}$ & $\mathbf{0 . 0 1 4}$ & $\mathbf{0 . 0 0 3 6 8}$ & $\mathbf{0 . 0 0 0 6 8}$ & $\mathbf{0 . 0}$ \\
\hline
\end{tabular}

Table 6: Volume does in direction (B) across shielding.

\begin{tabular}{|c|c|c|c|c|c|}
\hline Position & 4 & 3 & 2 & 5 & 7 \\
\hline Dose (rem/h) & $\mathbf{6 0 . 1 0}$ & $\mathbf{3 1 . 8 4}$ & $\mathbf{1 0 . 1 5}$ & $\mathbf{3 . 9 8}$ & $\mathbf{0 . 0}$ \\
\hline
\end{tabular}

Table 7: Volume does in directions (C) and (D) across shielding.

Directions(C)

\begin{tabular}{|c|c|c|}
\hline Position & 26 & 25 \\
\hline Dose (rem/h) & $1 \times 10^{-6}$ & $\mathbf{0 . 0}$ \\
\hline
\end{tabular}

Directions (D)

\begin{tabular}{|c|c|c|}
\hline Position & 20 & 27 \\
\hline Dose (rem/h) & $\mathbf{0 . 3 1 6}$ & $\mathbf{0 . 0}$ \\
\hline
\end{tabular}

6.5 Volume dose at water treatment plant (deionizer).

Table 8: Volume dose at position 14 in direction (E) across shielding at normal operation.

\begin{tabular}{|c|c|c|c|c|c|c|}
\hline Position & 4 & 18 & 17 & 16 & 15 & 14 \\
\hline Dose (rem/h) & $\mathbf{6 0 . 1}$ & $\mathbf{3 1 . 8 4}$ & $\mathbf{1 0 . 1 3}$ & $\mathbf{3 . 1 2}$ & $\mathbf{0 . 0 0 0 2 8}$ & $\mathbf{0 . 0 0}$ \\
\hline
\end{tabular}

Table 9: Volume dose at position 14 in direction (E) across shielding at abnormal operation (broken hot capsule).

\begin{tabular}{|c|c|c|c|c|c|c|}
\hline Position & 4 & 18 & 17 & 16 & 15 & 14 \\
\hline Dose (rem/h) & 59.8 & 30.43 & 9.2 & 2.08 & $\mathbf{0 . 0 0 0 0 9}$ & 0.12 \\
\hline
\end{tabular}

Table 10: Volume dose at various positions in the proposed design and its maze.

\begin{tabular}{|c|c|c|c|c|c|c|c|c|c|c|c|c|c|}
\hline Position & 4 & 18 & 17 & 16 & 15 & 14 & 33 & 34 & 35 & 36 & 37 & 38 & 36 \\
\hline Dose $($ rem/h) & $\mathbf{5 9 . 8}$ & $\mathbf{3 0 . 4 3}$ & $\mathbf{9 . 2}$ & $\mathbf{2 . 0 8}$ & $\mathbf{0 . 0 0 0 0 9}$ & $\mathbf{0 . 1 2}$ & $\mathbf{0 . 0 0 0 7}$ & $\mathbf{0 . 0 0 0 2}$ & $\mathbf{0 . 0 0 0 1}$ & $\mathbf{0 . 0}$ & $\mathbf{0 . 0}$ & $\mathbf{0 . 0}$ & $\mathbf{0 . 0}$ \\
\hline
\end{tabular}


$>$ Dose level outside the irradiation canyon is zero.

$>$ Does level at the entrance of each of the three mazes is zero.

$>$ Dose level outside the proposed design is zero.

$>$ Dose level inside proposed room $0.12(\mathrm{rem} / \mathrm{h})$, ozone exhaust duct is zero and also inside the four leg of proposed maze is zero.

\section{RESULTS AND DISCUSSION.}

The danger strike between radiation source rack components (vertical motion) and the edge of metallic container (horizontal motion) leads to repetitions falling cobalt-60 radiation capsules (pencils) from their modules safe positions inside storage pool and source shrouds maintain safe falling for capsules inside storage pool.

Probabilities of bending any hot capsules and sometimes a cobalt-60 capsule are broken and falls inside storage water pool and becomes open source. Cobalt-60 broken capsule is leakage. Cobalt-60 sources will precipitate on the water pool bottom. Water treatment plant (deionizer system) removes anions and cautions from water storage pool and also avoiding potential electrolytic corrosion of source stainless steel capsules and other metal components in water pool. Cobalt-60 sources will precipitate on the water pool bottom. The deionizer monitor detects and discovers cobalt-60 capsule that become open source inside water storage pool through fault signal (high radiation) will appear on control panel. The pump of deionizer system will stop and radiation source rack will fall down inside water storage pool. An audible and visual alarm will activate and operators will be instructed to evacuate cobalt-60 industrial irradiator and the main environment around it.

\section{CONCLUSION.}

There is a necessity need to modify concrete shielding of cobalt-60 western industrial irradiator (wet - storage) to contain water treatment plant inside the proposed calculated concrete shielding design. The proposed design has a new maze that leads from outside through four legs to proposed shielded room of water treatment plant and this room has sliding steel door with dimensions (high $230 \mathrm{~cm}$, width $120 \mathrm{~cm}$ and thickness $11.5 \mathrm{~cm}$ ). The proposed design of the (deionizer room) has two entrances where steel shielded door and concrete maze opening.

Radiation safety is maintained where the proposed concrete design prevents radiation exposure from contaminated water treatment plant when any hot capsule is broken and falls inside water of storage pool. The environment around industrial irradiator becomes safe in this case.

\section{The following dose measures are demonstrated:}

Dose level outside proposed concrete design is natural background.

$>$ Dose level at the end proposed leg is natural background and also is natural background outside sliding steel shielded door. Environment outside proposed design records safe radiation safety.

The results of dose rate values at different positions inside and outside the proposed design have proved that radiation safety outside the modified design is maintained.

The deionizer pump was equipped by an electronic sensor to automatically close or locked the door of the deionizer room and switch of the pump to prevent the discharge of deionizer waste water to the normal sewage to prevent the public and environment pollution.

All radiological measurements in case of normal operation are safe.

On the other hand, the radiological measurement in case of one capsule break is about $0.12 \mathrm{rem} / \mathrm{hr}$ which is dangerous for personnel and this value becomes zero after the design and execution of the new proposal as shown in Table 11.

* It should be noted that all radiological measurements after execution of the new proposal were found to be safe in all points outside the shielding of the deionizer room. 


\section{REFERENCES.}

1. INTERNATIONAL ATOMIC ENERGY AGENCY, (2005), "Gamma Irradiators for Radiation Processing”, IAEA DGPF/CD, Vienna.

2. Barabanova, A., J. R. Croft, and D. M. Delves. (1990),"The radiological accident in Soreq." Vienna: IAEA: 1-72.

3. IAEA - International Atomic Energy Agency. (1990)," The radiological accident in San Salvador", Vienna, IAEA, 1990.

4. A.E. Solyman, M.R. Roman, A.B. Keshk and K.A. Sharshar, (2016)," Design and Simulation of 5-DOF Vision-Based Manipulator to Increase Radiation Safety for Industrial Cobalt-60 Irradiators", Arab Journal of Nuclear Science and Applications, 94 (3), (250-261).

5. Keshk, A.B., (2003), "The Environmental Assessment for Design of Industrial Irradiation construction”, Ain Shams University.

6. Mehta. K., (2008), "Gamma Irradiator for Radiation Sterilization Trends in Radiation Sterilization of Health Care Products". I.A.E.A. VIENNA.

7. INTERNATIONAL ATOMIC ENERGY AGENCY, (2003), Practice specific model regulations, "Radiation safety of nonmedical irradiation facilities", IAEA-TECDOC-1367, Vienna.

8. INTERNATIONAL ATOMIC ENERGY AGENCY, (2004), "Emerging applications of radiation processing", IAEA-9. TECDOC-1386, Vienna.

9. INTERNATIONAL ATOMIC ENERGY AGENCY, (2010), "Radiation Safety of Gamma, Electron and X Ray Irradiation Facilities", IAEA Safety Standards Series No. SSG-8, IAEA, Vienna.

10. Modarres, M., (2010): "Reliability Engineering \& Risk Analysis: A practical Guide", vol. 349, $2^{\text {nd }}$ ed. CRC Press, pp. $100-$ 101.

11. U.S.EPA. Radiation Protection (2009): Facility Safety and Environmental Impact Environmental Protection Agency.

12. International Commission on Radiation Units and Measurements (1998). "Fundamental Quantities and Units for Ionizing Radiation", ICRU Report 60, ICRU, Bethesda, MD.

13. INTERNATIONAL ORGANIZATION FOR STANDARDIZATION, Radiation Protection (1998): "Sealed Radioactive Sources - General Requirements and Classification", ISO 2919, ISO, Geneva.

14. Coppell, D., Latham, I., and Nazarov, M. (2004): "cobalt-60 production in Russia and beyond", Radiat. Phys. Chem. 7 (14) 573-576.

15. Keshk. A. B., and Shosha, B.W. (2011):” A Proposed Design of Mechanical System of Industrial Cobalt 60 Irradiation Facility". Journal of Radiation Research and Applied Sciences Vol.3, No.4 (B), p.1385-1397.

16. Brinston, R.M., Levesque, D.G. (2004):" Irradiation on a new scale: Introducing Brevion", Emerging Applications of Radiation Processing, IAEA-TECDOC- 1386, 162 IAEA, Vienna.

17. Calvo, W.A.P (2004): "A small size continuous runs industrial gamma irradiator”, Radiat. Phys. Chem. 71 (2004) $561-$ 563.radaccidents.html (April 2006).

18. AMERICAN NATIONAL STANDARDS INSTITUTE, (2001),"Safe design and use of panoramic, wet source storage irradiators (Category IV)", ANSI-N43.10-1984, New York

19. International Atomic Energy Agency (1996). "Manual on panoramic gamma irradiators (categories II and IV)", Practical Radiation Safety Manual, Vienna.

20. MDS Nordion. (1999): Cobalt60 Irradiator JS - 9500 Tote IR - 206 NCRRT, Egypt. Operator's Manual.

21. ARY DE ARAUJO RODRIGUES JUNIOR, (2018), "INDUSTRIAL IRRADIATORS AND THEIR RADIOPROTECTION", 1st Edition, Maringa - PR Brazil.

22. WILSON APARECIDO PAREJO CALVO, (2005), "DEVELOPMENT OF AN IRRADIATION SYSTEM FOR A SMALL SIZE CONTINUOUS RUN MULTIPURPOSE GAMMA IRRADIATOR”, University of Sao Paulo.

23. Institute of Isotopes Co., Ltd. (2007), IRRADIATION FACILITY ALEXANDRIA, NCRRT, Egypt, TECHNICAL DOCUMENTATION, WATER TREATMENT UNIT.

24. A. Hamza Khalifa, A.B. Keshek, M.M. Aflfy, (2019), "New Design Vision of Swinging Steel Shielded Door for Safety Enhancement in Medical Radiological Linear Accelerator Facility" IJO-JOURNAL OF APPLIED SCIENCE, Vol. 2, No. 3

25. Vujo DRNDAEVI (2008): "Control of Gamma Irradiation Facility with improved Safety System", Nuclear Science and Technology. 45: 4, 361- 307.

26. J. Meissner, Kishor Mehta, A.G. Chmielewski, (2008) "Radiation safety at irradiation facilities", IAEA TECDOC. 